\title{
Conductive Thermoplastic Starch (TPS) Composite Filled with Waste Iron Filings
}

\author{
Danilo Battistelli ${ }^{a}$, Diana P. Ferreira ${ }^{b}$, Sofia Costa ${ }^{b}$, Carlo Santulli ${ }^{a^{*}}$, Raul Fangueiro ${ }^{b}$ \\ ${ }^{a}$ School of Architecture and Design, Università di Camerino, Viale Della Rimembranza 9, 63100 Ascoli Piceno, Italy \\ ${ }^{b}$ Centre for Textile Science and Technology (2C2T), University of Minho, 4800 Guimarães, Portugal.
}

\begin{abstract}
A thermoplastic starch (TPS) was produced, starting with potato starch, glycerol and acetic acid, to shape it in films of thickness around 100 microns. To TPS iron waste filing particles, in the amount of $12 \%$ the weight of starch, were introduced in different modalities: as received, reduced in size by the use of a mortar, after treatment with hydrochloric acid, and after treatment and removal of hydrochloric acid. Morphological studies were carried out by optical and scanning electron microscopy and illustrated that the dispersion of iron filings was not optimal, though some improvement was observed by a reduced dimension of the particles. Tensile tests indicated the considerable improvement of stiffness offered by the insertion of iron particles to TPS, although the ultimate strain was reduced to less than $10 \%$. Thermal characterization using thermogravimetry allowed revealing the three typical peaks for potato starch degradation, with only a slight decrease due to iron introduction. EDS allowed evaluating the presence of impurities in the iron filings and evidenced that the presence of iron was more effective on the surface than in the rest of the film. As a final consideration, An improvement in electrical conductivity by over an order of magnitude was obtained by the TPS $+\mathrm{Fe}+\mathrm{HCl}$ film with respect to pure TPS.
\end{abstract}

\section{Keywords:}

Iron Waste;

Starch;

Composites;

Electrical Conductivity;

Mechanical Properties.

Article History:

Received: $\quad 16$ February 2020

Accepted: 09 May 2020

Published: 01 June 2020

\section{1- Introduction}

Scrap iron, in the form of filings of random size and geometry, though prevalently powder, is a copious waste in blacksmith operations. This waste has found limited use so far. Two possible sectors are the treatment of hazardous materials e.g., for reduction of hexavalent chromium to trivalent one [1] or the filling of other materials with the aim to modify their properties e.g., in concrete for energy storage [2]. The problem of waste does not directly concern large steel works, which have from a few decades developed policies leading in recent years to "zero waste strategies" [3]. In contrast, the use of scrap iron powder as material filler faces some difficulties in environments, such as small blacksmith workshops, technical schools, etc.: here, it is normally disposed of as a special waste, even involving some costs, while on the other side re-using it in new materials might represent an opportunity. Of course, this kind of application would encounter a number of issues; the most relevant is initially the need for adequate filtering of the iron scrap powder, clearing it from extraneous substances, such as dust, while obtaining less scattered dimensions.

A possibility would be to take advantage of the electrical conductivity of this waste to confer them to other materials, which typically have limited conductivity, such as biopolymers, but increasingly used for their biodegradability and end of life. Among these, the production of thermoplastic starches (TPS) with high contents of glycerol, therefore with a starch/glycerol ratio around 1, leads to mixtures with sufficient tensile strength so to be extruded, which may be simply produced [4]. On the other side, the addition of acetic acid has an effect of

\footnotetext{
* CONTACT: Carlo.santulli@unicam.it

DOI: http://dx.doi.org/10.28991/esj-2020-01218
}

(C) 2020 by the authors. Licensee ESJ, Italy. This is an open access article under the terms and conditions of the Creative Commons Attribution (CC-BY) license (https://creativecommons.org/licenses/by/4.0/). 
plasticization and reduces melting temperature of thermoplastic starch, easing processing [5]. The particular interest of TPS is that it proved suitable to be adapted to the introduction of fillers in powder form, such as clay, even if only a limited control of their dimensions is applied [6]. In a number of cases, TPS obtained by simple processes were also able to effectively include waste: most attempts were performed with ligneous secondary raw matter, and TPS demonstrated to be quite resistant to rot and degradation during normal use [7-8]. The considerable cost of conductive polymer structures, which are obtained normally through appropriate doping [9], or by the introduction of carbon nanofibres [10], does indicate that the use of waste filler could be an option. In the case of starch-based bioplastics, which have a limited conductivity with appropriate electrolytes, such as ammonium nitrate, this emerges as particularly reasonable [11]. This would offer more guarantees for the potential application in the chassis of cell phones as a conductive yet sustainable, material [12] or other possibilities, such as conductive packaging, which have still now been proposed with complex materials, such as polyaniline filled with titanium dioxide nanowires [13].

Preliminary work has demonstrated that by introducing unfiltered iron scrap powder in the production of a thermoplastic starch, based on corn starch, glycerol and acetic acid, carrying out moulding of the material on a glass support with the introduction of $0.8 \mathrm{wt}$ \% of waste, sufficient tensile resistance was obtained [14]. Howe ver, concerns were raised on the dimension of filler particles, the presence of contaminants and the eventual formation of rust, which could affect the results. The present work is aimed at solving these two problems, hence contamination and dimensional control of the filler, additionally coming as far as to the assessment of electrical conductivity, which had not been measured before.

\section{2- Materials and Methods}

\section{2-1-Materials}

The iron powder was obtained by a local workshop in L'Aquila, Italy, which was disposing of it as special waste. Glacial acetic acid 99-100\% a.r., with $1.05 \mathrm{~g} / \mathrm{ml}$ density at $20{ }^{\circ} \mathrm{C}$ and $60.05 \mathrm{~g} / \mathrm{mol}$ molecular weight was supplied by ChemLab. Hydrochloric acid with density $1.16 \mathrm{~g} / \mathrm{ml}$ at $20{ }^{\circ} \mathrm{C}$, molecular weight of $36.46 \mathrm{~g} / \mathrm{mol}$, boiling point $75{ }^{\circ} \mathrm{C}$, and concentration above $33 \%$ was supplied by José Manuel Gomes Dos Santos. Potato starch and glycerol were purchased from Sigma-Aldrich and Scharlau, respectively.

\section{2-2- Films' Production}

The production of TPS films with and without Fe particles was carried out using solvent casting technique. Several conditions were tested including the addition of $\mathrm{HCl}$ and the use of mortar in order to optimize the developed films. Six different configurations of the films were evaluated, as schematically represented in Figure 1.

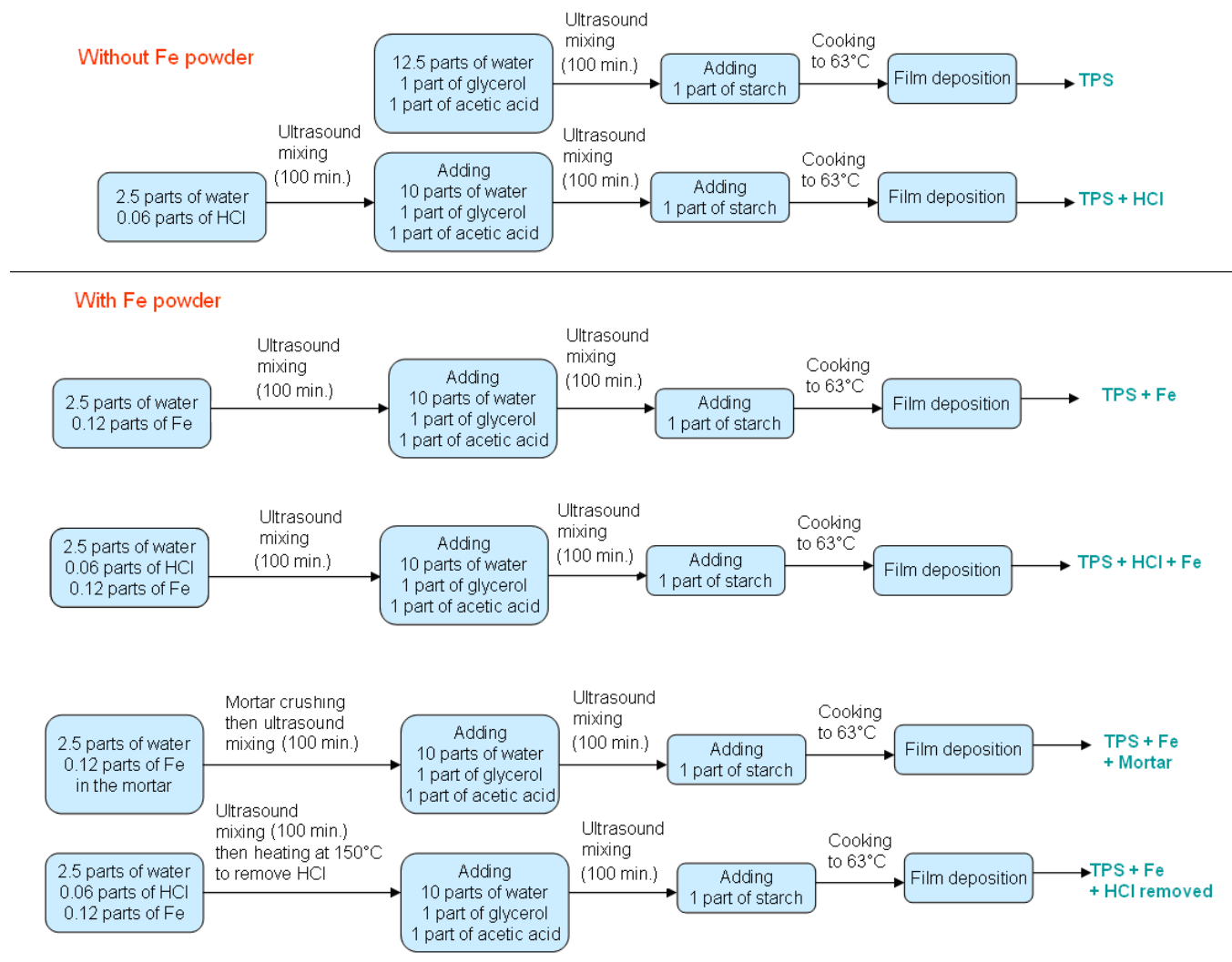

Figure 1. Schematic methodology used for the preparation of the different films by solvent casting technique. 
The six different configurations of material produced are reported in a schematic way in Figure 1. In particular, an equal amount of starch, of acetic acid and of glycerol, added to act as plasticizer agent, was used throughout the process. The polymeric solution was heated to $63{ }^{\circ} \mathrm{C}$ for $6 \pm 1$ minute hours. Finally, the solutions were poured into glass plates and dried at ambient temperature for 3 days. For the production of TPS/Fe films, the Fe particles were added in an initial stage. The use of $\mathrm{HCl}$ and mortar on the final films' properties was also evaluated.

\section{2-3- Films' Characterization}

\section{2-3-1- Films' Thickness}

The films' thickness was measured in different locations using a digital micrometer. The mean value was calculated.

\section{2-3-2- Optical Microscopy}

An optical microscope (Leica DM750 M(bright-field)) was used to evaluate the presence and dispersion of Fe particles into TPS films.

\section{2-3-3- Field Emission Scanning Electron Microscopy (FESEM) and Energy Dispersive Spectroscopy (EDS)}

The surface and the cross-section morphology of the TPS films with and without Fe particles was visualized by FESEM analysis using a NOVA 200 Nano SEM from FEI Company (Hillsboro, OR, USA). Before the experiment, all the samples were coated with a very thin film $(20 \mathrm{~nm})$ of Au-Pd (80-20 weight \%). Images were taken in topographic mode with an accelerated voltage of $10 \mathrm{kV}$. Atomic contrast images were realized with BSED detector at an acceleration voltage of $15 \mathrm{kV}$. The elemental composition of the films was evaluated by EDS technique (Hillsboro, OR, USA) coupled to FESEM, using an EDAX Si (Li) detector with $15 \mathrm{kV}$ of acceleration voltage.

\section{2-3-4- Thermogravimetric Analysis (TGA)}

In order to evaluate the thermal stability of the samples, TGA analysis was performed using a STA 700 da SCANSCI. The samples were heated from room temperature to $700{ }^{\circ} \mathrm{C}$ with a heating rate of $10{ }^{\circ} \mathrm{C} / \mathrm{min}$ under nitrogen flow.

\section{2-4- Functional Properties Evaluation}

\section{2-4-1- Mechanical Properties}

Tensile tests were performed in a Hounsfield Tinius Olsen testing machine model H100KPS in displacement control mode, with a cross-head speed equal to $10 \mathrm{~mm} / \mathrm{min}$ and an initial grip separation of $50 \mathrm{~mm}$. Rectangular films samples were cut in with $90 \mathrm{~mm}$ length and $10 \mathrm{~mm}$ width. Tensile strength (TS), elongation at break (EB) and Young's modulus were determined. Five replicates of each sample were evaluated.

\section{2-4-2- Electrical Conductivity}

The electrical resistivity of each sample was measured using a picometer/voltage source (Keitley 487), where the applied voltage ranged from -0.8 to $0.8 \mathrm{~V}$, at room temperature. The electrical resistivity $(\rho)$ was calculated by:

$\rho=R \times \frac{A}{L}$

Where $\mathrm{R}$ represents the electrical resistance, $\mathrm{A}$ is the area of the electrode $\left(5 \times 1 \mathrm{~mm}^{2}\right)$, and $\mathrm{L}$ is the distance between the electrodes $(3 \mathrm{~mm})$. The electrical resistance was obtained through de slope values of the I-V curves. Finally, the electrical conductivity $(\sigma)$ was determined by the inverse of electrical resistivity, as shown by the following equation:

$\sigma=\frac{1}{\rho}$

\section{3- Results and Discussion}

\section{3-1- Optical Microscopy}

In an initial stage, the presence and the dispersion of Fe particles into TPS films was evaluated by optical microscopy. Figure 2 shows the micrographs at different magnifications of the six different configurations developed. The comparison between the different materials identifies that hydrochloric acid produces an increased number of cavities in TPS structure, in some cases also connected with a rougher appearance. In the configurations with added iron particles, they tend also to agglomerate, a trend that appear less diffuse in the case in which a mortar grinding is also used. On the other side, the removal of hydrochloric acid from films including iron particles results in more complex patterns of distribution of the particles. 

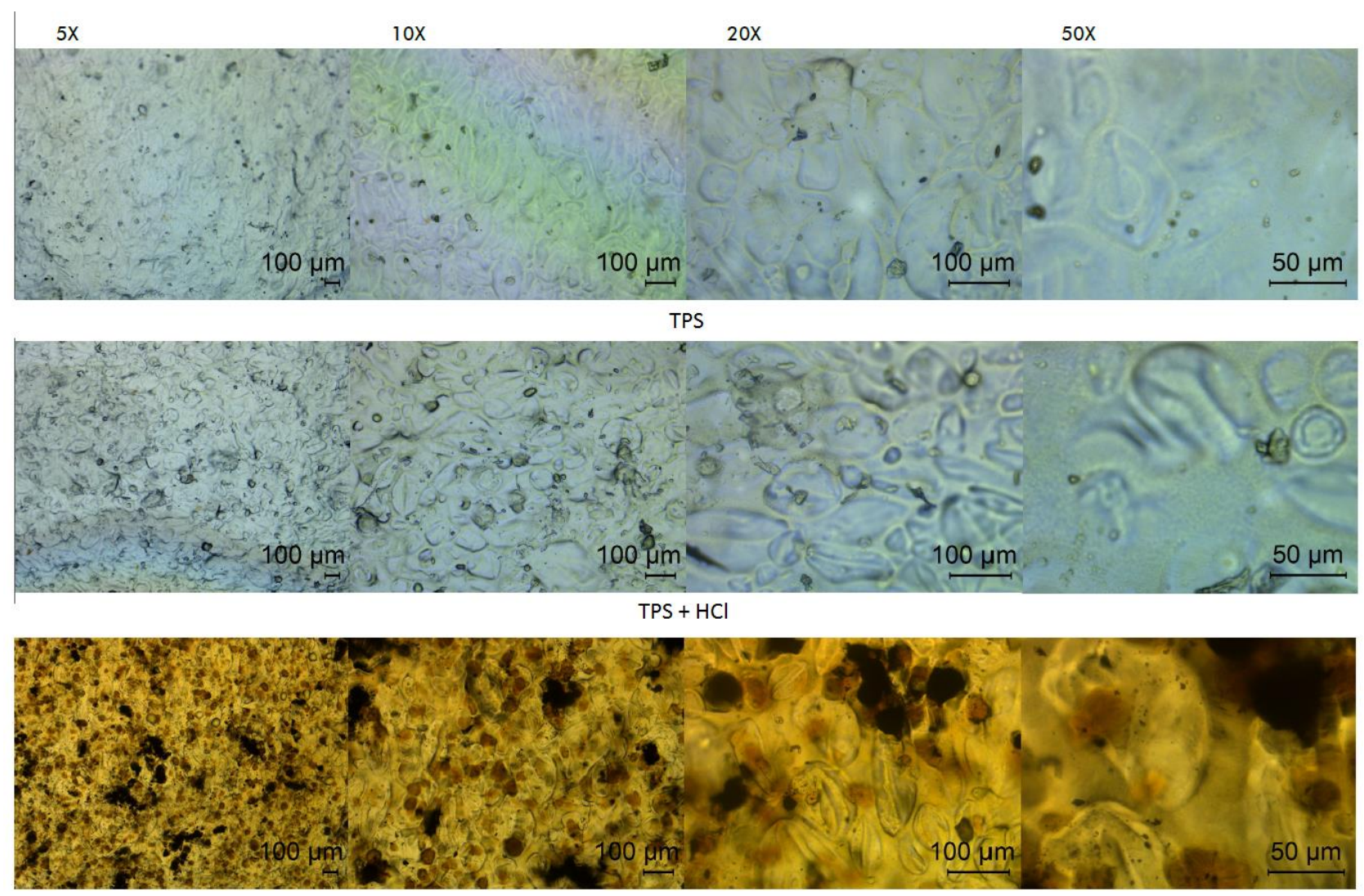

$\mathrm{TPS}+\mathrm{Fe}$

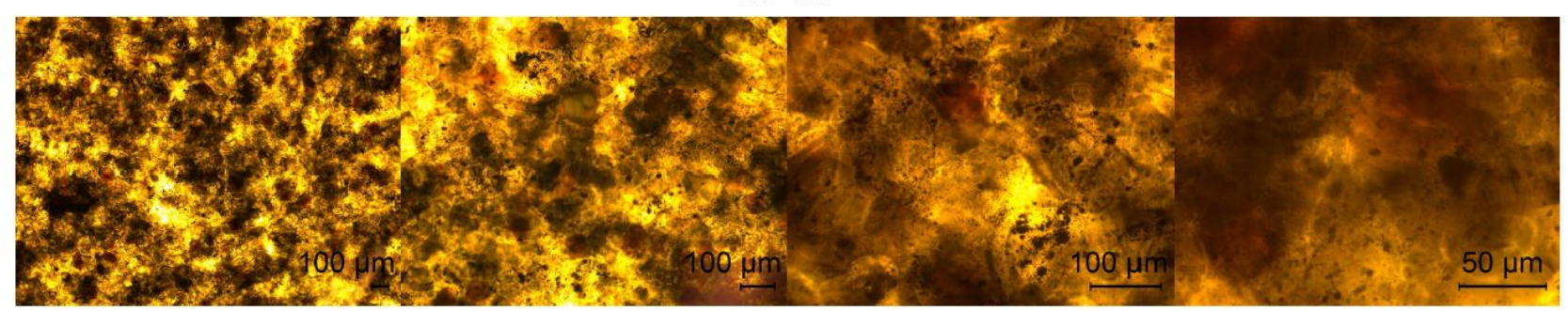

TPS + Fe (mortar)

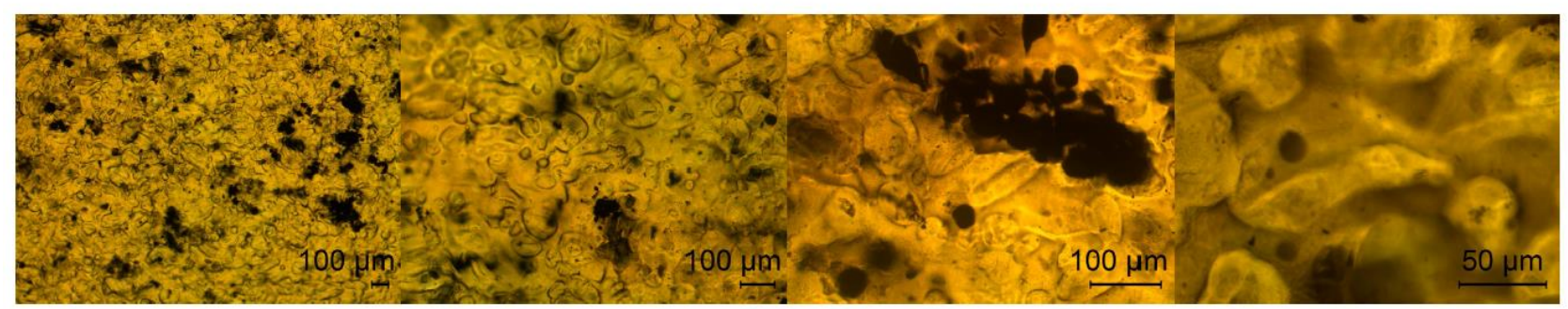

$\mathrm{TPS}+\mathrm{HCl}+\mathrm{Fe}$

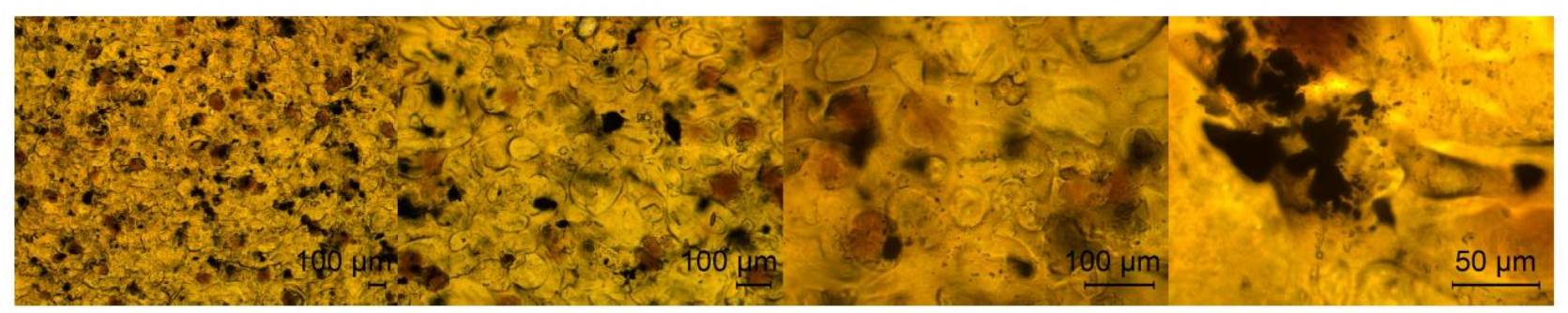

$\mathrm{TPS}+\mathrm{HCl}$ removed $+\mathrm{Fe}$

Figure 2. Optical micrographs of the different films' configurations at different magnifications.

\section{3-2- Morphology and Elemental Composition Analysis}

In order to evaluate the surface as well as the cross-section morphology of the developed films, FESEM analysis was performed, as shown in Figures 3 and 4, respectively. 


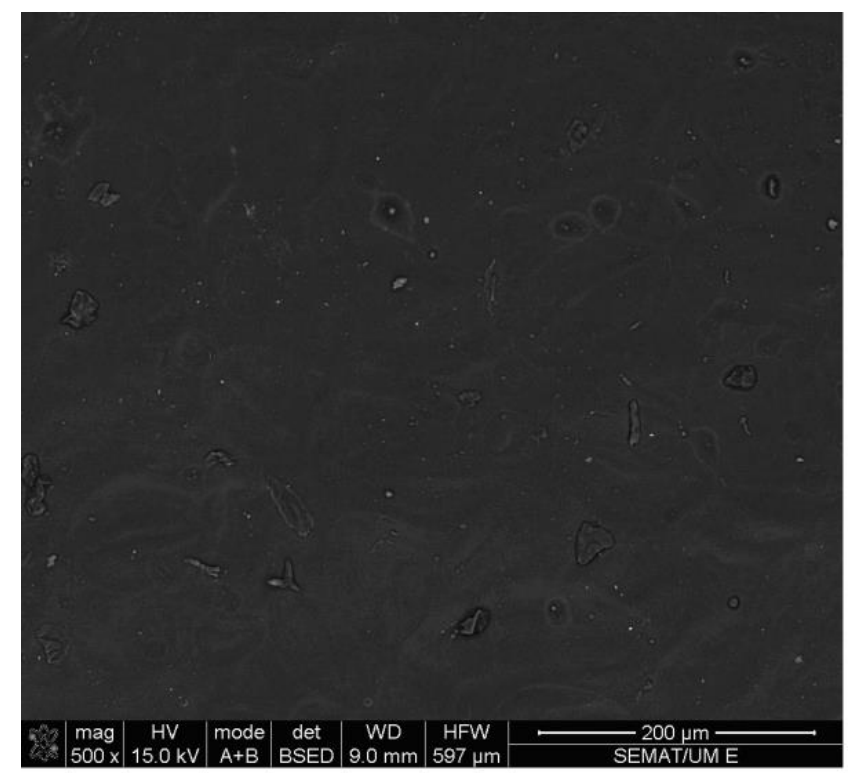

TPS

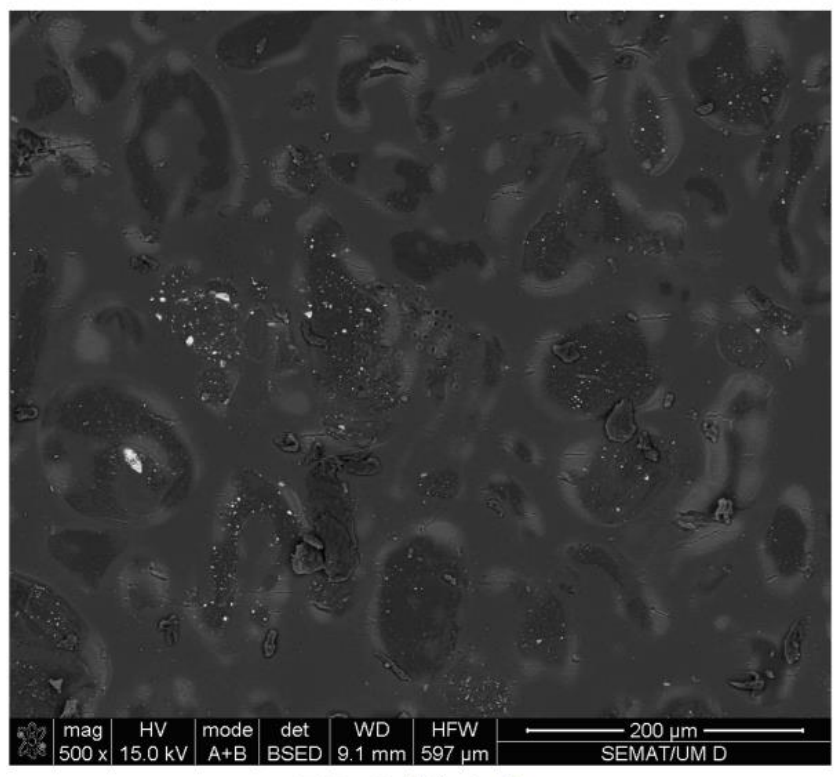

TPS + Fe ( Mortar)

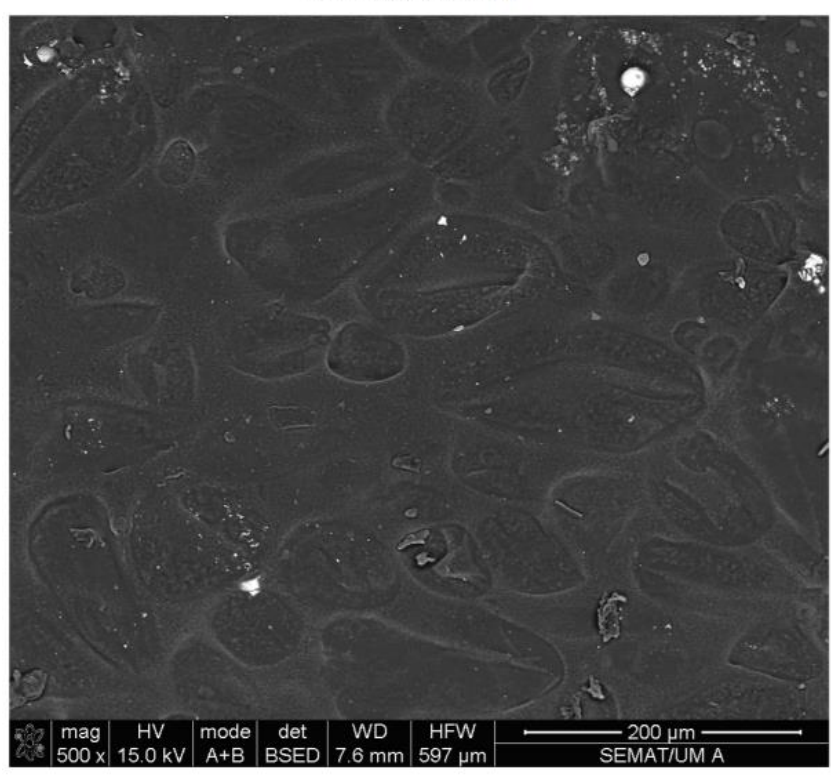

$\mathrm{TPS}+\mathrm{HCl}+\mathrm{Fe}$

Figure 3. FESEM images of the surface of TPS, TPS+Fe (Mortar) and TPS+HCl+Fe films, with magnifications of $200 \mu \mathrm{m}$. 


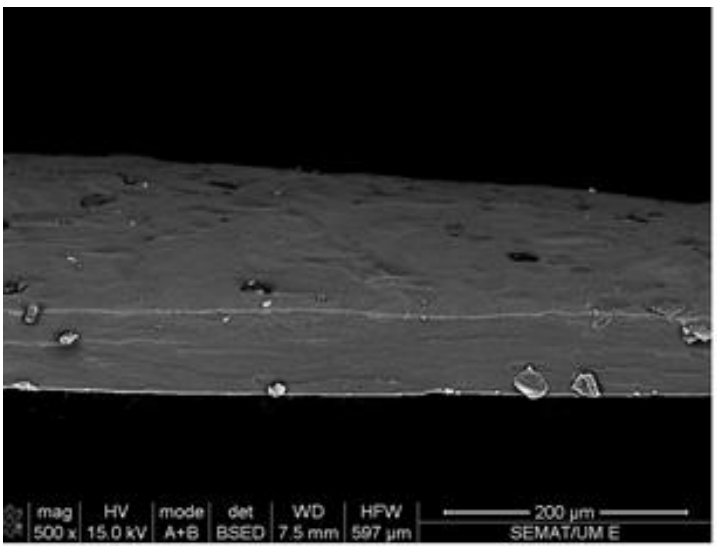

TPS

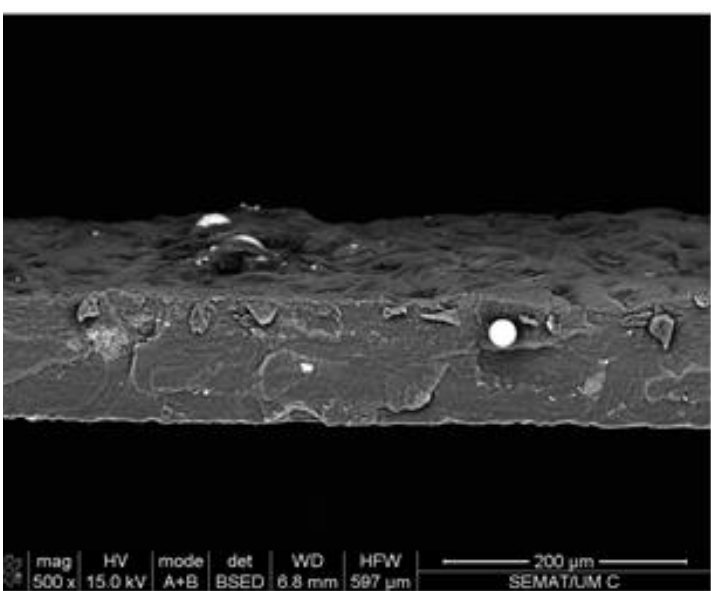

TPS + Fe

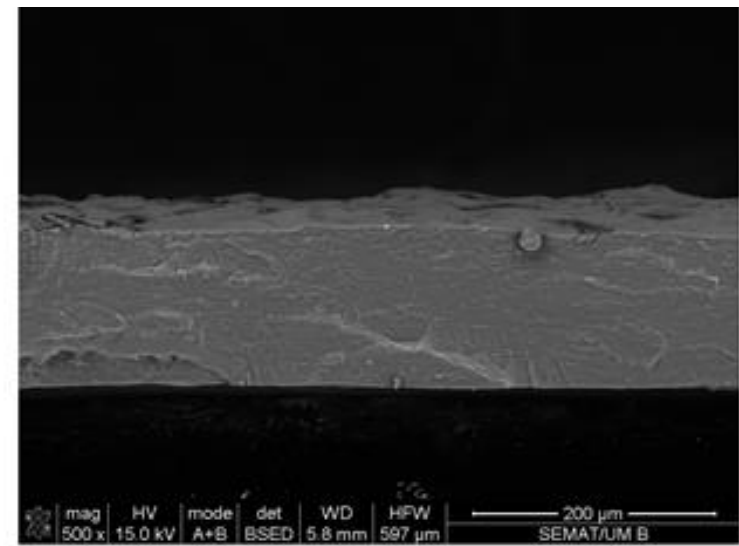

$\mathrm{TPS}+\mathrm{HCl}$

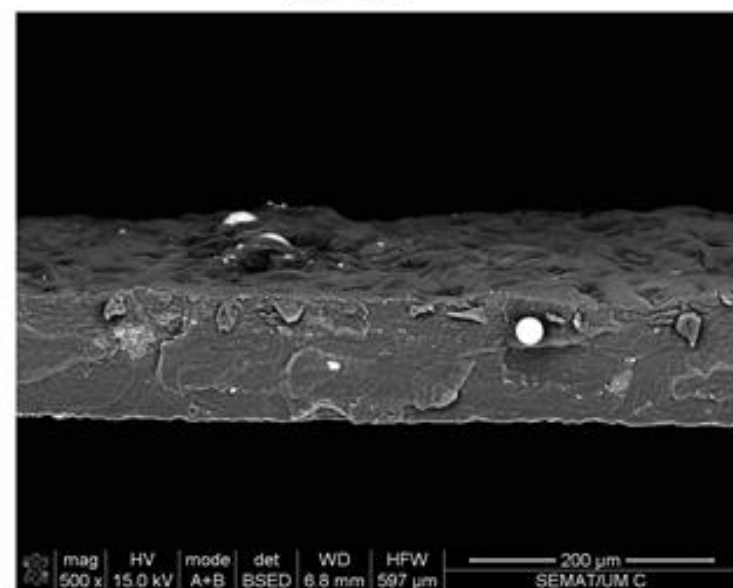

$\mathrm{TPS}+\mathrm{HCl}+\mathrm{Fe}$

Figure 4. FESEM micrographs of the films' cross-section with magnifications of $200 \mu \mathrm{m}$.

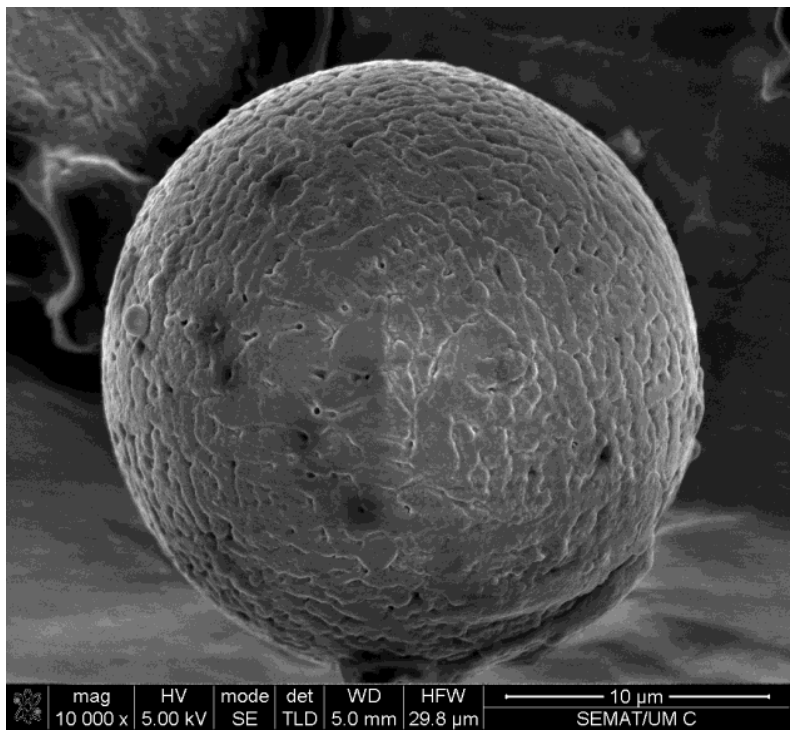

Figure 5. A typical iron particle used for introduction into TPS detached from the film surface.

From Figure 3 (films' surface) and Figure 4 (films' cross-section) it is possible to observe the presence of Fe particles into TPS films. Moreover, the introduction of these particles promotes an increase in surface roughness. This confirms both the higher roughness obtained in configurations treated with hydrochloric acid and the evidence that an improved interfacial mixing is obtained through mortar grinding of metal particles. These are well visible though, if this was not the case, both at some depth in the film and surfacing from it.

Finally, Figure 5 shows a single iron particle, which is detached from the film surface and only slightly bonded with some other material at the bottom. In general terms, this did not demonstrate to be a very diffuse occurrence, 
although it is particularly possible for particles of sufficiently small dimension, in the specific case the diameter of the particle was around 15 microns.

EDS analysis was also performed in surface and cross-section of the films containing iron particles in order to evaluate the elemental composition, as demonstrated in Figure 6.

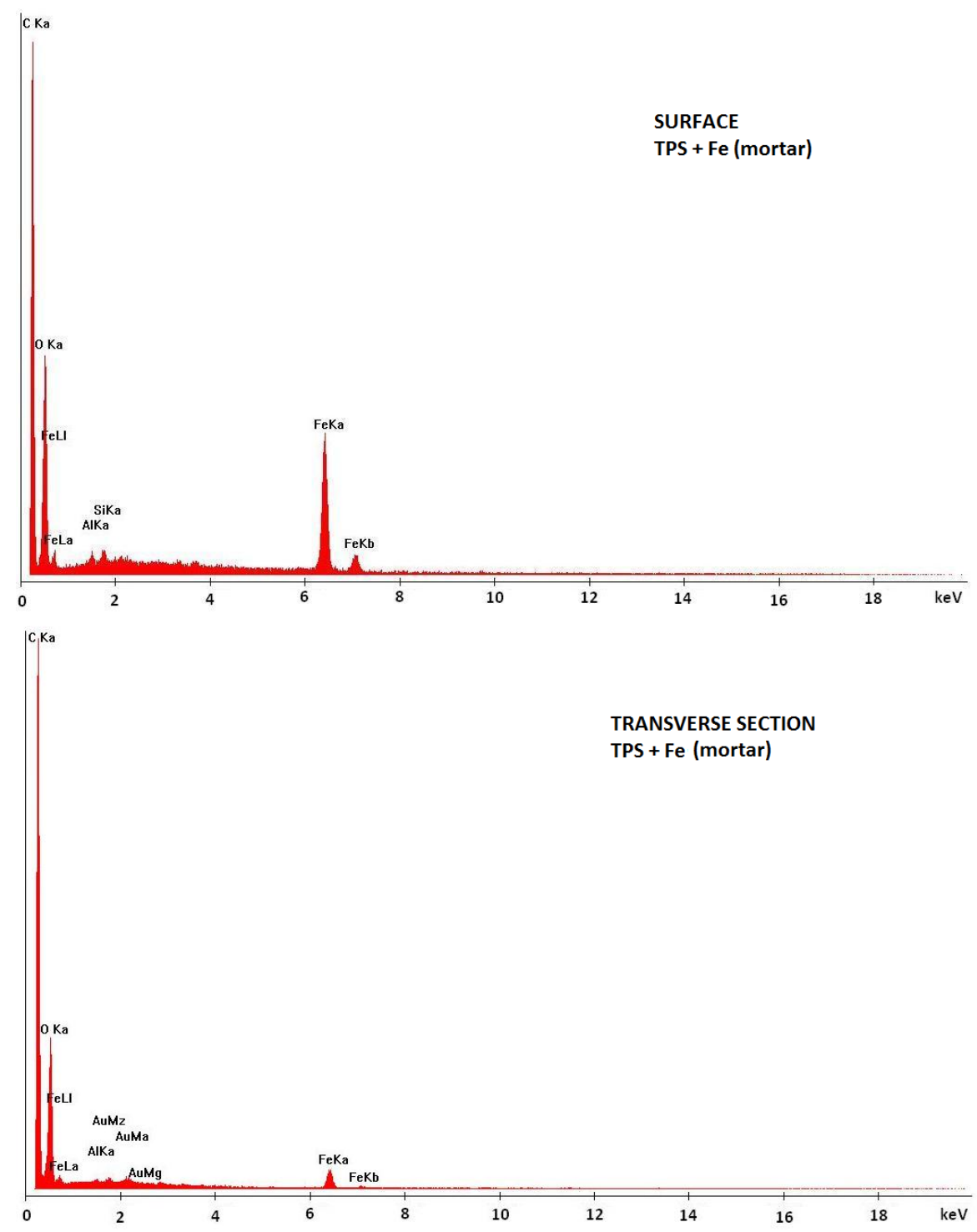

Figure 6. EDS analysis of the composition and impurities of the iron filings particles.

This analysis shows the presence of carbon and oxygen elements, which are the main constituents of starch and especially glycerol, since the former does not always give very recognizable signals [15]. Furthermore, it is also possible to confirm the presence of iron particles, particularly in the films' surface, as demonstrated by the different evidence of the peaks of $\mathrm{Fe}$ at 6.4 and $7.1 \mathrm{keV}$, values which appear to be typical [16]. Other peaks can be also observed, which can be attributed to the impurities in iron filings, especially related to some silica, therefore due to the presence of inert materials, such as sand, and also other metals, in particular aluminium and gold. This does depend on the source of iron filings, and on mechanical operations from which these were obtained: other works report e.g., the possible presence of titanium [17]. This could lead to variability in electrical conductivity to be further investigated in the future, although purification of filings e.g., by magnetic processes, would possibly improve the quality of the filler, although it would also entail further costs.

\section{3-3- Thermal Stability}

In order to evaluate the thermal stability of the developed films, TGA analysis was performed. The samples were subjected to a heating process until $700{ }^{\circ} \mathrm{C}$ and the degradation profiles were evaluated. Figure 7 demonstrates the TG and the first order derivative (DTG) curves of each sample. 

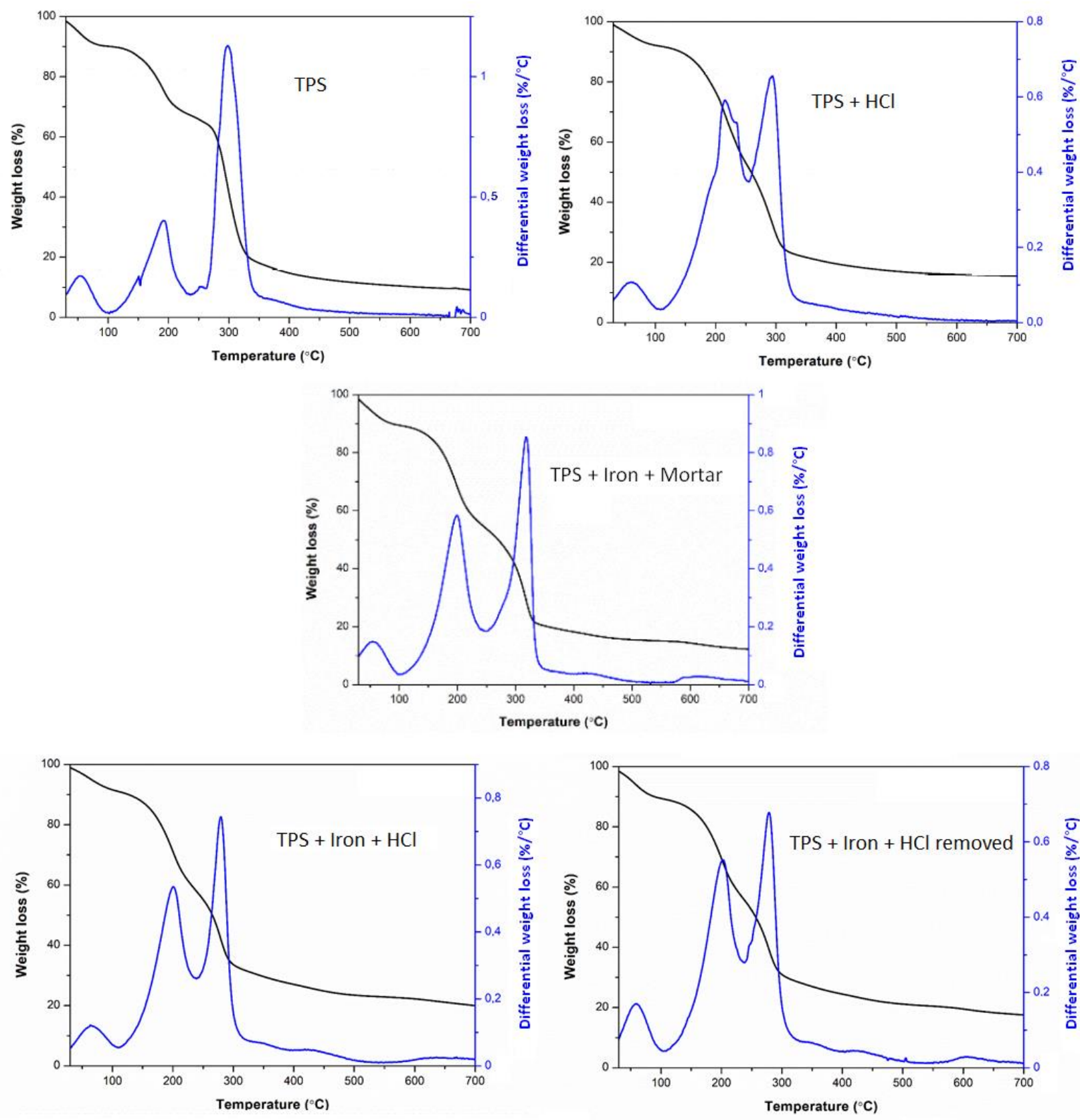

Figure 7. TG (represented in black) and DTG (represented in blue) curves of the different developed films.

From Figure 7 it is possible to observe that TPS has three main thermal degradation stages, as was reported already by several studies [18-19]. The first one around $30{ }^{\circ} \mathrm{C}$ and $105{ }^{\circ} \mathrm{C}$ corresponds to water evaporation. The second one located between $105{ }^{\circ} \mathrm{C}$ and $250{ }^{\circ} \mathrm{C}$ is attributed to glycerol degradation. Finally, the third step is from starch degradation, which occurs between $250{ }^{\circ} \mathrm{C}$ and $350{ }^{\circ} \mathrm{C}$. It has been reported that for high glycerol contents glass transition temperature are lower than ambient temperature [20]. The temperature for film deposition was selected with the idea not to lead to excessive water loss, while obtaining sufficient mechanical properties. The three peaks observed from the thermogravimetric analysis (TGA) curves, reported in Figure 2, refer to progressive loss of water, then above $100{ }^{\circ} \mathrm{C}$ to the loss of water and plasticizers, mainly acetic acid, and finally to TPS decomposition [21]. In particular, potato starch plasticized with glycerol was attributed a decomposition temperature not far from $300{ }^{\circ} \mathrm{C}$ in previous studies [22-23]. The three peaks observed are reported in Table 1: it can be highlighted, as the hydrochloric acid is able to delay the temperature of degradation of plasticizers. Moreover, its use in combination with iron powder results in the preservation of a higher weight of material preserved (up to around $20 \%$ the initial weight) preserved after starch decomposition. 
Table 1. Thermogravimetric analysis results.

\begin{tabular}{cccc}
\hline Material & First peak $\left({ }^{\circ} \mathbf{C}\right)$ & Second peak $\left({ }^{\circ} \mathbf{C}\right)$ & Third peak $\left({ }^{\circ} \mathbf{C}\right)$ \\
\hline TPS & 58 & 190 & 305 \\
TPS $+\mathrm{HCl}$ & 62 & 215 & 307 \\
TPS $+\mathrm{Fe}($ Mortar $)$ & 56 & 199 & 316 \\
TPS $+\mathrm{HCl}+\mathrm{Fe}$ & 62 & 203 & 280 \\
TPS $+\mathrm{HCl}$ removed $+\mathrm{Fe}$ & 56 & 192 & 277 \\
\hline
\end{tabular}

\section{3-4- Mechanical Properties}

In order to evaluate the influence of iron particles in mechanical properties of the developed films, tensile tests were performed. Tensile tests indicate a large scattering of results among the different samples, as reported in Figure 8. This appears to be an inherent characteristic of TPS, produced by film deposition without therefore using dedicated moulds, and has been described already in previous studies [24]. As reported in Table 2, the introduction of iron particles results in a reduction of the ultimate strain of the TPS, which is not surprising due to the higher rigidity obtained. This was the result that was expected, considering that iron filings were not supposed to have effect on tensile strength, as it was clarified even when higher contents of it were introduced in harder matrices, such as concrete [25]. On the other side, the large presence of glycerol leads to low tensile strength, yet to retaining a sufficient elongation at break [26]. The use of the mortar to further decompose metal particles does allow obtaining a strain close to $20 \%$, much larger than without this pre-processing of waste; in this way, the dispersion of iron is also promoted. Using unprocessed iron particles as filler does also result in lower thickness, as from Table 3, but this, as observed in Figure 1, depends on the formation of clusters of particles tending to aggregate into TPS, which is not so apparent instead whenever these have been further chopped using the mortar. Aggregates are also present in further configurations including with hydrochloric acid, which on the other side produces roughness, likely to result in uneven shrinkage, and the creation of porosities, such as it is observed already in the TPS $+\mathrm{HCl}$ configuration. It is well known as potato starch-based TPS usually presents some patchy regions with diffuse roughness, and treatment with hydrochloric acid does increase this occurrence, whilst on the other side it also yields a higher conductivity, as from data in Table 4.
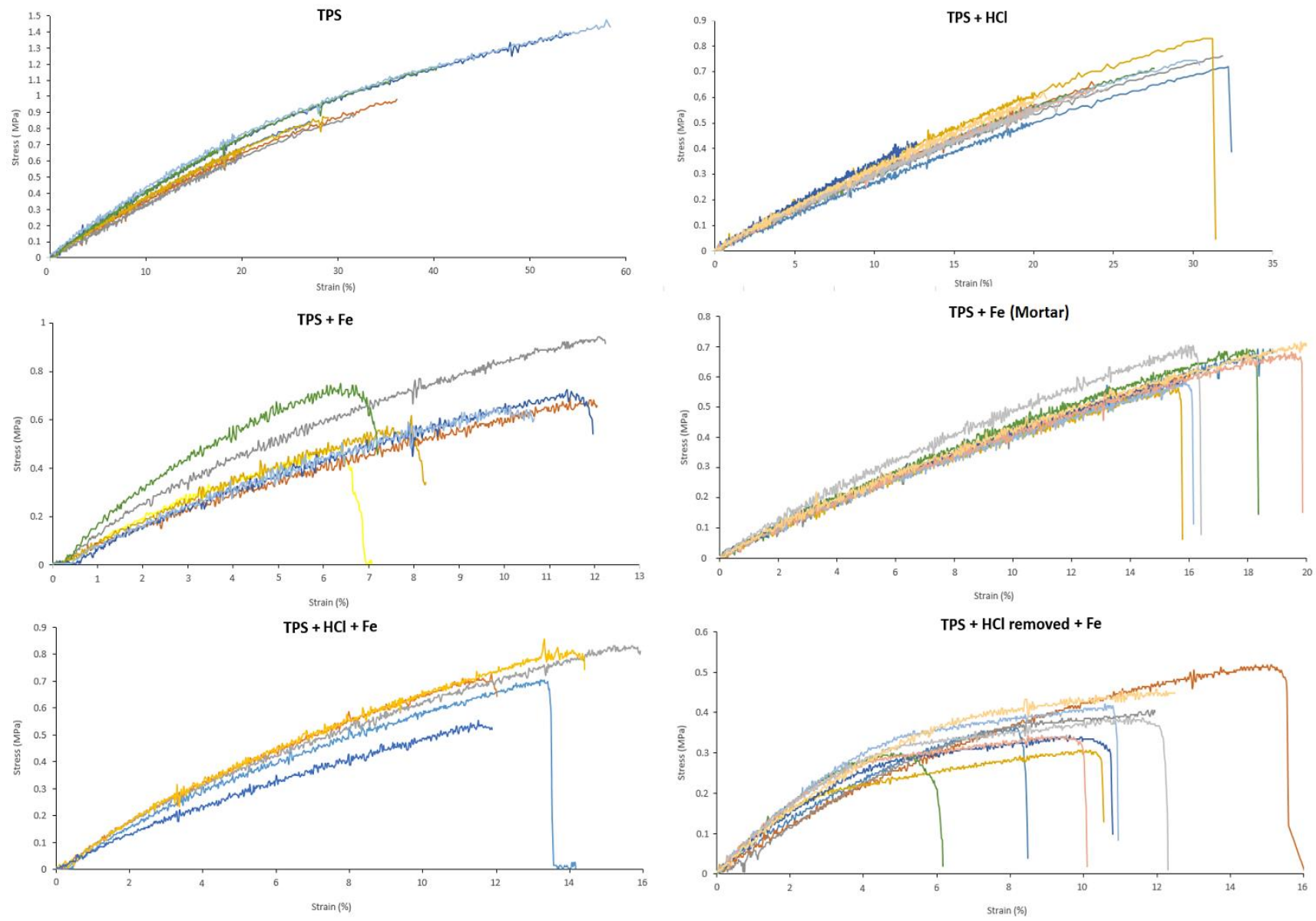

Figure 8. Tensile curves for the different test samples of all material configurations. 
Table 2. Mechanical properties of the different material configurations.

\begin{tabular}{cccc}
\hline Material & Tensile strength (MPa) & Elongation at break (\%) & Young's modulus (MPa) \\
\hline TPS & $1.09 \pm 0.24$ & $39.6 \pm 11.4$ & $2.75 \pm 0.70$ \\
TPS + HCl & $0.70 \pm 0.09$ & $27.8 \pm 4.9$ & $2.52 \pm 0.38$ \\
TPS + Fe & $0.70 \pm 0.12$ & $9.9 \pm 2.2$ & $7.07 \pm 1.32$ \\
TPS + Fe (Mortar) & $0.66 \pm 0.05$ & $18 \pm 1.8$ & $3.67 \pm 0.32$ \\
TPS + HCl + Fe & $0.74 \pm 0.11$ & $13.8 \pm 1.2$ & $5.36 \pm 0.63$ \\
TPS + HCl removed + Fe & $0.38 \pm 0.07$ & $11.1 \pm 2.9$ & $3.42 \pm 0.75$ \\
\hline
\end{tabular}

Table 3. Thickness of the different material configurations.

\begin{tabular}{cc}
\hline Material & Film thickness $(\boldsymbol{\mu m})$ \\
\hline TPS & $102 \pm 10$ \\
TPS $+\mathrm{HCl}$ & $147 \pm 9$ \\
TPS + Fe & $105 \pm 11$ \\
TPS $+\mathrm{Fe}$ (Mortar) & $161 \pm 12$ \\
TPS $+\mathrm{HCl}+\mathrm{Fe}$ & $153 \pm 6$ \\
TPS $+\mathrm{HCl}$ removed $+\mathrm{Fe}$ & $158 \pm 14$ \\
\hline
\end{tabular}

\section{3-5- Electrical Conductivity}

Conductive tests were performed in order to evaluate the incorporation of iron particles into TPS electrical properties. The obtained values of electrical conductivity of the different developed films are demonstrated in Table 4.

Table 4. Electrical conductivity of the different material configurations.

\begin{tabular}{cc}
\hline Material & Electrical conductivity $(\mathbf{S} / \mathbf{m})$ \\
\hline TPS & $6.67 \times 10^{-4}$ \\
TPS + HCl & $4.49 \times 10^{-3}$ \\
TPS + Fe & $1.51 \times 10^{-3}$ \\
TPS + Fe (Mortar) & $4.00 \times 10^{-4}$ \\
TPS + HCl + Fe & $7.42 \times 10^{-3}$ \\
TPS + HCl removed + Fe & $3.55 \times 10^{-3}$ \\
\hline
\end{tabular}

Through Table 4 it is possible to observe that the incorporation of iron particles into TPS films increased the electrical conductivity values from $6.67 \times 10^{-4}$ to $1.51 \times 10^{-3} \mathrm{~S} / \mathrm{m}$, which would be expected since these particles are conductive materials. However, the use of mortar with the consequent reduction of particles dimension, did not improve electrical conductivity $\left(4.00 \times 10^{-4} \mathrm{~S} / \mathrm{m}\right)$.

Also the use of $\mathrm{HCl}$ in TPS films promoted an increase of the electrical conductivity values from $6.67 \times 10^{-4}$ to $4.49 \times 10^{-3} \mathrm{~S} / \mathrm{m}$.

As the predicted consequence, the sample that presented the highest electrical conductivity properties $\left(7.42 \times 10^{-3}\right)$ was the TPS film with $\mathrm{HCl}$ and incorporated with iron particles, which showed a synergy of the two aforementioned effects.

The combined effect cannot be classified as outstanding, which is due to the not large amount of iron particles introduced, limited by their not very effective dispersion. Yet it is promising, in view of the improvement of electrical conductivity, which in the best case exceeds one order of magnitude.

\section{4- Conclusion}

The introduction of waste iron filings, reduced to particles with dimensions around 15 microns, in a thermoplastic starch (TPS) matrix, based on potato starch and glycerol treated with acetic acid proved suitable for the production of films with thickness in the order of 150 microns. Both the mechanical grinding of the particles in a mortar and the introduction, then removal, of hydrochloric acid in TPS allowed improving the dispersion of iron particles. The combined action of hydrochloric acid and the addition of iron particles improved the electrical conductivity.

The possible future development of this experimentation would require making more repeatable the production of TPS and the distribution of iron particles over the whole volume of the polymer film, bearing in mind that the use of 
waste iron filings would have significance as such. If these aims are fulfilled, this would have an interest as a biodegradable slightly conductive and antistatic plastic film.

\section{5- Conflict of Interest}

The author declares that there is no conflict of interests regarding the publication of this manuscript. In addition, the ethical issues, including plagiarism, informed consent, misconduct, data fabrication and/or falsification, double publication and/or submission, and redundancies have been completely observed by the authors.

\section{6- References}

[1] Gheju, M, and A Iovi. "Kinetics of Hexavalent Chromium Reduction by Scrap Iron.” Journal of Hazardous Materials 135, no. 1-3 (July 31, 2006): 66-73. doi:10.1016/j.jhazmat.2005.10.060.

[2] Adeyanju, A.A., and K. Manohar. "Effects of Steel Fibers and Iron Filings on Thermal and Mechanical Properties of Concrete for Energy Storage Application.” Journal of Minerals and Materials Characterization and Engineering 10, no. 15 (2011): 14291448. doi:10.4236/jmmce.2011.1015111.

[3] Sahay JS; Nagpal OP. Prasad S, Waste management of steel slag, Steel Times International; Redhill 24 (2), 2000, 38-40, 43.

[4] Rodriguez-Gonzalez, F.J., B.A. Ramsay, and B.D. Favis. "Rheological and Thermal Properties of Thermoplastic Starch with High Glycerol Content." Carbohydrate Polymers 58, no. 2 (November 2004): 139-147. doi:10.1016/j.carbpol.2004.06.002.

[5] Shogren, R.L. "Modification of Maize Starch by Thermal Processing in Glacial Acetic Acid." Carbohydrate Polymers 43, no. 4 (December 2000): 309-315. doi:10.1016/s0144-8617(00)00178-8.

[6] Park, Hwan - Man, Xiucuo Li, Chang - Zhu Jin, Chan - Young Park, Won - Jei Cho, and Chang - Sik Ha. "Preparation and properties of biodegradable thermoplastic starch/clay hybrids." Macromolecular Materials and Engineering 287, no. 8 (2002): 553-558. doi:10.1002/1439-2054(20020801)287:8<553::AID-MAME553>3.0.CO;2-3.

[7] Troiano, M., C. Santulli, G. Roselli, Girolami Di, P. Cinaglia, and A. Gkrilla. "DIY Bioplastics from Peanut Hulls Waste in a Starch-Milk Based Matrix.” FME Transactions 46, no. 4 (2018): 503-512. doi:10.5937/fmet1804503t.

[8] Galentsios, Chiara, Carlo Santulli, and Mirco Palpacelli. "DIY bioplastic material developed from banana skin waste and aromatised for the production of bijoutry objects." Journal of Basic and Applied Research International (2017): 138-150.

[9] Chiang, C. K., C. R. Fincher, Y. W. Park, A. J. Heeger, H. Shirakawa, E. J. Louis, S. C. Gau, and Alan G. MacDiarmid. “Electrical Conductivity in Doped Polyacetylene." Physical Review Letters 39, no. 17 (October 24, 1977): $1098-1101$. doi:10.1103/physrevlett.39.1098.

[10] Yang, Y., M. C. Gupta, K. L. Dudley, and R. W. Lawrence. "Conductive Carbon Nanofiber-Polymer Foam Structures." Advanced Materials 17, no. 16 (August 18, 2005): 1999-2003. doi:10.1002/adma.200500615.

[11] Khiar, A. S. Ahmad, and A. K. Arof. “Conductivity Studies of Starch-Based Polymer Electrolytes.” Ionics 16, no. 2 (May 28, 2009): 123-129. doi:10.1007/s11581-009-0356-y.

[12] Liao, Chi-Shun, Kuo-Ren Lou, and Ching-Tzu Gao. "Sustainable Development of Electrical and Electronic Equipment: UserDriven Green Design for Cell Phones.” Business Strategy and the Environment 22, no. 1 (March 21, 2012): 36-48. doi:10.1002/bse.743.

[13] Youssef, Ahmed M. "Morphological Studies of Polyaniline Nanocomposite Based Mesostructured TiO2 Nanowires as Conductive Packaging Materials." RSC Advances 4, no. 13 (2014): 6811. doi:10.1039/c3ra44658a.

[14] Battistelli, Danilo, and Carlo Santulli. 2019. "Production and Tensile Characterization of Thermoplastic Starch Films Filled With Iron Scrap Powder Waste and Molded on Different Support Materials". Journal of Materials Science Research and Reviews 3 (4), 1-8.

[15] Lai, Vivian M.-F., Piotr Tomasik, Ming-Tsung Yen, Wei-Ling Hung, and Cheng-yi Lii. "Re-Examination of the Interactions Between Starch and Salts of Metals from the Non-Transition Groups.” International Journal of Food Science and Technology 36, no. 3 (March 2001): 321-330. doi:10.1046/j.1365-2621.2001.t01-1-00463.x.

[16] Shen, Yi, Lidija Posavec, Sreenath Bolisetty, Florentine M. Hilty, Gustav Nyström, Joachim Kohlbrecher, Monika Hilbe, et al. “Amyloid Fibril Systems Reduce, Stabilize and Deliver Bioavailable Nanosized Iron.” Nature Nanotechnology 12, no. 7 (April 24, 2017): 642-647. doi:10.1038/nnano.2017.58.

[17] Zhong, Hua, Mark L. Brusseau, Yake Wang, Ni Yan, Lauren Quig, and Gwynn R. Johnson. "In-Situ Activation of Persulfate by Iron Filings and Degradation of 1,4-Dioxane." Water Research 83 (October 2015): 104-111. doi:10.1016/j.watres.2015.06.025.

[18] Estevez-Areco, Santiago, Lucas Guz, Lucía Famá, Roberto Candal, and Silvia Goyanes. "Bioactive Starch Nanocomposite Films with Antioxidant Activity and Enhanced Mechanical Properties Obtained by Extrusion Followed by ThermoCompression.” Food Hydrocolloids 96 (November 2019): 518-528. doi:10.1016/j.foodhyd.2019.05.054. 
[19] García, Nancy L., Laura Ribba, Alain Dufresne, Mirta Aranguren, and Silvia Goyanes. "Effect of Glycerol on the Morphology of Nanocomposites Made from Thermoplastic Starch and Starch Nanocrystals." Carbohydrate Polymers 84, no. 1 (February 2011): 203-210. doi:10.1016/j.carbpol.2010.11.024.

[20] Rodriguez-Gonzalez, F.J., B.A. Ramsay, and B.D. Favis. "Rheological and Thermal Properties of Thermoplastic Starch with High Glycerol Content." Carbohydrate Polymers 58, no. 2 (November 2004): 139-147. doi:10.1016/j.carbpol.2004.06.002.

[21] Jiugao, Yu, Wang Ning, and Ma Xiaofei. "The Effects of Citric Acid on the Properties of Thermoplastic Starch Plasticized by Glycerol.” Starch - Stärke 57, no. 10 (October 2005): 494-504. doi:10.1002/star.200500423.

[22] Sessini, Valentina, Marina P. Arrieta, José Maria Kenny, and Laura Peponi. "Processing of Edible Films Based on Nanoreinforced Gelatinized Starch.” Polymer Degradation and Stability 132 (October 2016): 157-168. doi:10.1016/j.polymdegradstab.2016.02.026.

[23] Musa MB, Yoo MJ, Kang TJ, Kolawole EG, Ishiaku US, Yakubu MK, Whang DJ, Characterization and thermomechanical properties of thermoplastic potato starch, Research and Reviews: Journal of Engineering and Technology 2 (4), 2013, 9-16.

[24] Scognamiglio, Fabrizio, Daniele Mirabile Gattia, Graziella Roselli, Franca Persia, Ugo De Angelis, and Carlo Santulli. “Thermoplastic Starch Films Added with Dry Nopal (Opuntia Ficus Indica) Fibers." Fibers 7, no. 11 (November 19, 2019 ): 99. doi:10.3390/fib7110099.

[25] Alzaet AN, Effect of iron filings in concrete compression and tensile strength, International Journal of Recent Development in Engineering and Technology 3 (4), 2014, 121-125.

[26] Li, Hongbo, and Michel A. Huneault. "Effect of Chain Extension on the Properties of PLA/TPS Blends." Journal of Applied Polymer Science 122, no. 1 (April 19, 2011): 134-141. doi:10.1002/app.33981. 